\title{
Clinical Study \\ Retroperitoneal Laparoscopic Ureterolithotomy for Proximal Ureteral Calculi in Selected Patients
}

\author{
Qingfeng Hu, ${ }^{1,2,3}$ Weihong Ding, ${ }^{1,2,3}$ Yuancheng Gou, ${ }^{1,2,3}$ Yatfaat Ho, ${ }^{1,2,3} \mathrm{Ke} \mathrm{Xu,}{ }^{1,2,3}$ \\ Bin Gu, ${ }^{1,2,3}$ Chuanyu Sun, ${ }^{1,2,3}$ Guowei Xia, ${ }^{1,2,3}$ and Qiang Ding ${ }^{1,2,3}$ \\ ${ }^{1}$ Department of Urology, Huashan Hospital, Fudan University, No. 12 Central Urumqi Road, Shanghai 200040, China \\ ${ }^{2}$ Fudan Institute of Urology, Huashan Hospital, Fudan University, Shanghai 200040, China \\ ${ }^{3}$ Department of Surgery, Shanghai Medical College, Fudan University, Shanghai 200040, China \\ Correspondence should be addressed to Chuanyu Sun; zhugexianglong@163.com and Guowei Xia; xiaguowei@fudan.edu.cn
}

Received 22 July 2014; Revised 28 September 2014; Accepted 2 October 2014; Published 8 December 2014

Academic Editor: Olivier Traxer

Copyright (C) 2014 Qingfeng Hu et al. This is an open access article distributed under the Creative Commons Attribution License, which permits unrestricted use, distribution, and reproduction in any medium, provided the original work is properly cited.

Objectives. To summarize our experience of retroperitoneal laparoscopic ureterolithotomy for ureteral calculi and evaluate the safety and efficiency of this procedure. Methods. We conducted a retrospective analysis of 197 patients with proximal ureteral calculi who accepted retroperitoneal laparoscopic ureterolithotomy from June 2005 to June 2014. Results. All procedures were performed successfully and the mean operating time and estimated blood loss were $87 \mathrm{~min}$ and $64 \mathrm{~mL}$. The clearance rate was $98.5 \%$ and the rates of urine leak and ureteral stricture were $2.5 \%$ and $1.0 \%$. Conclusions. Retroperitoneal laparoscopic ureterolithotomy is a safe and effective procedure for patients with complex stones or anatomic abnormalities, and, with experience of high volume series, it is also a reasonable choice as the primary treatment for such selected patients.

\section{Introduction}

Urolithiasis is an extremely common disease, and the management of ureteral calculi has been changing since the appearance of shockwave lithotripsy (SWL), ureterorenoscopy (URS), and percutaneous nephrolithotomy (PNL). The aim of treatment is to achieve a stone-free status and protect the ipsilateral renal function as soon, as safely, and as minimally invasively as possible. However, the best treatment is still controversial, extremely for patients with complex ureteral stones or anatomic abnormalities. SWL should not be recommended as the first-line treatment option for the management of large ureteral stones with severe hydronephrosis [1]. And, with clearance rates of $60-90 \%$, URS and PNL could not obtain satisfactory results yet [2-4].

Ureterolithotomy is often accepted as an ultimate means for the most difficult stone and always occupies its place although SWL, URS, and PNL have brought about the revolutionary change to the management of proximal ureteral calculi [5]. Laparoscopy has provided a novel option for the replacement of conventional open surgery, and the advantages on analgesia, recuperation, hospital stay, and cosmetics over open surgery are obvious [6]. Although laparoscopic ureterolithotomy (LU) is not the first choice in most cases for its invasiveness, LU has the highest stonefree rate (SFR) compared to SWL and URS, and LU also has its unique advantages on patients with large impacted stone, severe hydronephrosis, or anatomic anomalies [7]. From our preliminary experience, we have recognized its potential and advantages in selected patients. Different from traditional consensus, LU could be accepted as a preferred choice and get effective clearance with fast recovery.

\section{Materials and Methods}

2.1. Enrolled Patients. A series of 197 patients with proximal ureteral calculi who accepted retroperitoneal LU in our center, Department of Urology, Huashan Hospital of Fudan University, from June 2005 to June 2014 were enrolled. The following information was collected retrospectively: gender, age, side and size of ureteral stones, operating time, blood loss, postoperative hospital stay, and complications. The clearance rate was also an important indicator to evaluate the result 


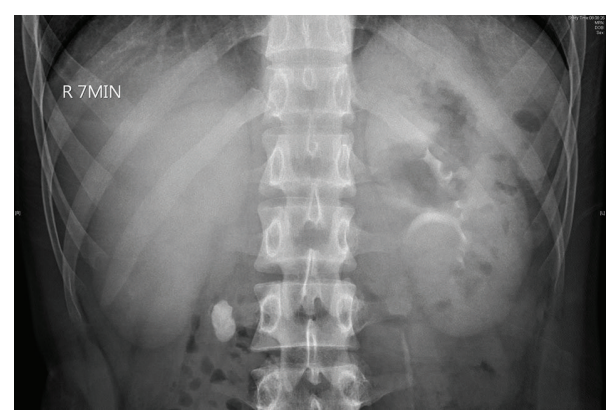

FIgURE 1

of LU, which was defined as the status of no residual stone in IVU and CT. All patients got the definite diagnosis before operation, from the results of ultrasonography, intravenous urography (IVU), and computed tomography (CT) (Figure 1). Not all patients would experience colic. Patients with one of the following indications would be considered to be suitable for LU: (a) proximal ureteral calculi larger than $1.5 \mathrm{~cm}$; (b) distal ureteral stricture with ureteral polypus or external compression. LU could also be considered for patients who suffered ureteral stones no larger than $1.5 \mathrm{~cm}$ but severe hydronephrosis without self-discharge for long course in follow-up, especially for those with abnormal anatomy or prior failure of treatment with SWL or URS. Calculi locating in proximal ureters which were from ureteropelvic junction to the upper edge of the pelvis would be considered to be treated with LU. The coinstantaneous renal stones were not treated in the same operation. When a patient suffered multiple ureteral stones in the same location, LU could be used to clear all visible stones. However, when a patient suffered multiple ureteral stones in different locations, LU would be used to clear the largest one, and the others could be cleared by SWL or URS. All patients were informed to follow up 1 to 3 months after operation. Ultrasonography and CT could be used to evaluate the hydronephrosis compared to that before operation; X-ray and IVU could be used to evaluate the residual status of stone and potential ureteral stricture after operation.

2.2. Operative Technique. All the operations were performed by one experienced surgeon (Guowei Xia) who did well in urologic laparoscopic surgery. LU was conducted by the conventional three ports procedure under a lateral decubitus position with hyperextension, which was reported in our previous similar study [8]. To establish working space, the fascia lumbodorsalis was divided by a hemostatic forceps through a $2 \mathrm{~cm}$ incision over the iliac crest, and the retroperitoneal fat and the retroperitoneal space were separated by the digital dissection and balloon dilatation. Two ports were guided by index finger and placed at the subcostal anterior and posterior axillary line, and the port of camera was at the former incision over the iliac crest. The ureteral stone could be identified along the bulge of ureter in the area anterior to the psoas major muscle after opening Gerota's fascia and renal capsule. The ureteral stone was extracted from a longitudinal incision, and a 6F D-J stent (Cook Medical) was inserted routinely

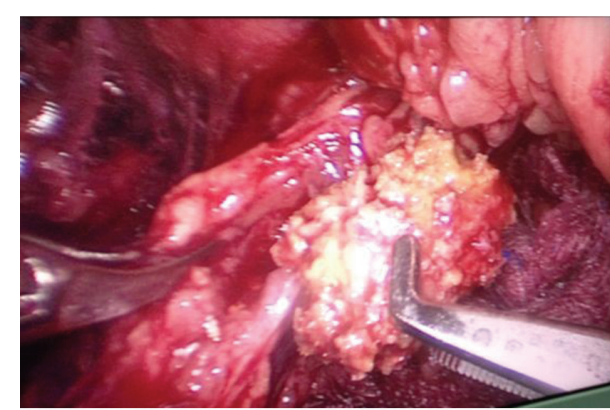

Figure 2

TABLE 1: The characteristics of patients and perioperative data.

\begin{tabular}{lc}
\hline Sex (male/female) & $116 / 81$ \\
Mean age (y) (range) & $41(20-73)$ \\
Side of disorder (left/right) & $89 / 108$ \\
Mean size of ureteral calculi (mm) (range) & $22(14-35)$ \\
Indications & $139(70.5)$ \\
$\quad$ Large stones & $47(23.9)$ \\
$\quad$ Abnormal anatomy or ureteral stricture & $11(5.6)$ \\
$\quad$ Severe hydronephrosis or prior failure of & \\
treatment with SWL or URS & $87(65-165)$ \\
Mean operating time (min) (range) & $64(20-150)$ \\
Mean estimated blood loss (mL) (range) & $3.6(2-7)$ \\
Postoperative hospital stay (d) (range) & $194(98.5)$ \\
Clearance in follow-up of four weeks (\%) & \\
Complications & $3(1.5)$ \\
$\quad$ Migration back to pelvis of calculi (\%) & $5(2.5)$ \\
Urine leak (\%) & $2(1.0)$ \\
$\quad$ Ureteral stricture (\%)
\end{tabular}

(Figure 2). The method used to insert D-J stent was similar to that mentioned by Fan and colleagues [9]. Then the ureteral incision could be closed by interrupted sutures. A retroperitoneal drain was inserted and removed once it was below $20 \mathrm{~mL}$, and the D-J stent would be extracted 3-4 weeks later by cystoscopy.

\section{Results}

The characteristics of patients and perioperative data were listed in Table 1. The mean size of ureteral calculi was $22 \mathrm{~mm}$, and all procedures were performed in laparoscopy with no conversion to open surgery. The average of operating time and estimated blood loss was $87 \mathrm{~min}$ and $64 \mathrm{~mL}$ and that of hospital stay and retroperitoneal drain was 3.6 days and 2.7 days (patients with urine leak excluded).

The clearance rates at discharge and four weeks later were $97.5 \%$ and $98.5 \%$. Three patients were found to have ureteral stones that migrated back to pelvis during operation and they accepted PNL later. The rates of urine leak and postoperative ureteral stricture were $2.5 \%(5 / 197)$ and $1.0 \%(2 / 197)$. To those with urine leak, the indwelling period of retroperitoneal 
TABle 2: Perioperative data of laparoscopic ureterolithotomy for ureteral calculi.

\begin{tabular}{|c|c|c|c|c|c|c|}
\hline Authors & Year & Cases & $\begin{array}{c}\text { Mean stone size } \\
(\mathrm{mm})\end{array}$ & $\begin{array}{c}\text { Mean operating } \\
\text { time } \\
(\mathrm{min})\end{array}$ & $\begin{array}{l}\text { Postoperative } \\
\text { hospital stay } \\
\text { (d) }\end{array}$ & $\begin{array}{c}\text { Stone-free } \\
\text { rate } \\
(\%)\end{array}$ \\
\hline Flasko et al. [13] & 2005 & 73 & 25 & 45 & 3.3 & 100 \\
\hline Kijvikai and Patcharatrakul [14] & 2006 & 30 & 19 & 121.4 & 3.9 & 100 \\
\hline El-Feel et al. [15] & 2007 & 25 & 19 & 145 & 4.1 & 100 \\
\hline El-Moula et al. [16] & 2008 & 74 & 18 & 58.7 & 6.4 & 100 \\
\hline Huri et al. [17] & 2010 & 41 & 22 & 124 & 4.8 & 100 \\
\hline Wang et al. [18] & 2010 & 36 & 17.3 & 131.5 & 5.8 & 100 \\
\hline Farooq Qadri et al. [19] & 2011 & 126 & 13.6 & 88 & 2.8 & 97.6 \\
\hline Leonardo et al. [20] & 2011 & 33 & 34 & 85 & 3.4 & 100 \\
\hline Ko et al. [21] & 2011 & 32 & 18.1 & 117.8 & 5.9 & 93.8 \\
\hline Basiri et al. [2] & 2008 & 50 & 22.4 & 127.8 & 5.8 & 90 \\
\hline Karami et al. [22] & 2013 & 40 & 13.5 & 82 & 3.5 & 100 \\
\hline Nasseh et al. [23] & 2013 & 33 & - & 85.5 & 4.1 & 93.9 \\
\hline Zhu et al. [4] & 2014 & 21 & 15 & 93.7 & 6.1 & 90.5 \\
\hline Current experience & 2014 & 197 & 22 & 87 & 3.6 & 98.5 \\
\hline
\end{tabular}

drain and D-J stent should extend, respectively, until recovery after about 6 weeks, and to those with postoperative ureteral stricture, they accepted ureteroscopy and dilatation three months after LU.

\section{Discussion}

The treatment of ureteral calculi has evolved in recent decades and the ultimate objects are clearance and minimal invasion. Current options including SWL and URS have the particular rates of clearance, complications, and limitations, respectively. However, large and impacted proximal stone is still a tricky problem whose treatment remains controversy. There is no doubt that SWL is the least invasive procedure, and the success rate is not that satisfactory. It is reported that the clearance rate after a single session of SWL would decrease from $83.6 \%$ to $42.1 \%$ when the stone is larger than $10 \mathrm{~mm}$ [10]. Although the improvement of equipment and technology enhances the ability of URS in the treatment of ureteral calculi, URS is still limited by its clearance rate and complications. An overall complication rate after URS is about $25 \%$ [11]; proximal location and stone impaction are common factors predicting unfavorable results [12].

Ureterolithotomy always has its place in the treatment of ureteral calculi, and laparoscopic surgery is increasingly replacing open surgery today. Although with higher morbidity than SWL and URS, LU could still be considered as a minimally invasive procedure. LU has its particular advantage in those with most complex stones, previous failed treatment of SWL or URS, and anatomical abnormalities. It is the most important that LU has the highest SFR compared to SWL and URS for proximal ureteral calculi [7]. According to our data and other published high volume studies, the advantage is obvious (Table 2) $[2,4,13-23]$. The procedure of LU is more complex than SWL and URS, and the operating duration is longer than SWL and URS [3].
However, LU seems to be not difficult and is associated with a short learning curve [9]. LU could achieve a high level of efficacy with low rates of complication. It is the main aspect of morbidity for LU to break the intraperitoneal or retroperitoneal structures and integrity of collecting system. It would be still considered less serious than the trauma from major complications in URS, such as ureteral perforation and ureteral avulsion, nevertheless. To try SWL or URS in every patient is meaningless and hazardous; it is more reasonable for patients to choose appropriate treatment depending on the situation.

The common and major complications of LU include stone migration, urine leak, and ureteral stricture. However, with low rates of complications, LU is an effective and safe procedure (Table 3). To confirm the location of stone, an Xray of kidney, ureter, and bladder (KUB) is needed routinely, and dissection of the ureter from the bulge to the stone site should be performed carefully to avoid stone migration. The appearance of migration often means failure of LU; open conversion or postponed PNL would increase the morbidity. A more common complication is urine leak, which is in the form of prolonged drainage and elevated creatine in it. We have experienced 5 cases, particularly in those with long course and inflamed edematous ureter. Placing a DJ stent plays an important role in prevention while it does not increase the duration of operation, and it should be accepted as a routine procedure [24]. Another complication is ureteral stricture, relatively. Stitching too tight or too loose is a common problem encountered by beginners; looseness is associated with urine leak while tightness is associated with ureteral stricture. Our experience implies that loose stitching should be more appropriate. Under the existence of D-J stent, most cases of urine leak would close up spontaneously in a prolonged period.

It is an interesting issue whether transperitoneal LU or retroperitoneal LU is more dominant. Generally, both 
TABLE 3: Complications of laparoscopic ureterolithotomy for ureteral calculi.

\begin{tabular}{lccccc}
\hline Authors & Year & Cases & $\begin{array}{c}\text { Stone migration } \\
(n, \%)\end{array}$ & $\begin{array}{c}\text { Urine leak } \\
(n, \%)\end{array}$ & $\begin{array}{c}\text { Ureteral stricture } \\
(n, \%)\end{array}$ \\
\hline Flasko et al. [13] & 2005 & 73 & - & $6,8.2$ & 0,0 \\
El-Moula et al. [16] & 2008 & 74 & $1,1.4$ & $1,1.4$ & $1,1.4$ \\
Huri et al. [17] & 2010 & 41 & $1,2.4$ & $5,12.2$ & $1,2.4$ \\
Farooq Qadri et al. [19] & 2011 & 126 & - & $3,2.4$ & - \\
Leonardo et al. [20] & 2011 & 33 & 0,0 & $1,3.0$ & 0,0 \\
Ko et al. [21] & 2011 & 32 & $2,6.3$ & $3,7.5$ & - \\
Karami et al. [22] & 2013 & 40 & - & 0,0 & $0,3.1$ \\
Nasseh et al. [23] & 2013 & 33 & $1,3.0$ & $5,2.5$ & $2,1.0$ \\
Current experience & 2014 & 197 & $3,1.5$ & & - \\
\hline
\end{tabular}

transperitoneal LU and retroperitoneal LU are effective, safe, and feasible, and the choice depends on personal preference and experience of surgeons [25]. Here, we prefer retroperitoneal LU, based on former experience in open and laparoscopic surgery for renal and ureteral diseases. Even more important, we believe that retroperitoneal LU would be associated with less morbidity and faster recovery, which would influence less intraperitoneal tissue and organs. Besides, transperitoneal approach would bring about the adhesion and modification of normal anatomy and create difficulties for possible intraperitoneal operations in the future. As a minimally invasive procedure, laparoscopic surgery is superior in the less influence and destruction of normal anatomic structure compared to open surgery, and so it is with retroperitoneal procedure to transperitoneal procedure.

Our study also has its limitations as a retrospective series in a single center. With lack of comparison, these results are not representative. SWL and URS are more likely to be accepted and are recommended as main methods for the treatment of ureteral calculi. Although LU could also provide satisfactory results, increased complexity and trauma would limit its application. In fact, considering the techniques and experience, together with the patients' conditions, the appropriate method is the best for patients. Additionally, we have just focused on the short-term prognosis of LU and have been short of long-term results. LU causes destruction for the normal structure of ureter after all. The long-term outcomes of LU remain unclear, which need further study to give robust conclusions.

\section{Conclusions}

As a safe and effective procedure for ureteral calculi, retroperitoneal LU is suitable for patients with complex stones or anatomic abnormalities and provides the highest SFR in the treatment of ureteral calculi. Indeed, with experience of high volume series, it is also a reasonable choice as the primary treatment for such selected patients.

\section{Conflict of Interests}

The authors declare that there is no conflict of interests regarding the publication of this paper.

\section{References}

[1] Y.-H. Lee, J.-Y. Tsai, B.-P. Jiaan, T. Wu, and C.-C. Yu, "Prospective randomized trial comparing shock wave lithotripsy and ureteroscopic lithotripsy for management of large upper third ureteral stones," Urology, vol. 67, no. 3, pp. 480-484, 2006.

[2] A. Basiri, N. Simforoosh, A. Ziaee, H. Shayaninasab, S. M. M. H. Moghaddam, and S. Zare, "Retrograde, antegrade, and laparoscopic approaches for the management of large, proximal ureteral stones: a randomized clinical trial," Journal of Endourology, vol. 22, no. 12, pp. 2677-2680, 2008.

[3] A. C. L. Neto, F. Korkes, J. L. Silva II et al., "Prospective randomized study of treatment of large proximal ureteral stones: extracorporeal shock wave lithotripsy versus ureterolithotripsy versus laparoscopy," The Journal of Urology, vol. 187, no. 1, pp. 164-168, 2012.

[4] H. Zhu, X. Ye, X. Xiao, X. Chen, Q. Zhang, and H. Wang, "Retrograde, antegrade, and laparoscopic approaches to the management of large upper ureteral stones after shockwave lithotripsy failure: a four-year retrospective study," Journal of Endourology, vol. 28, no. 1, pp. 100-103, 2014.

[5] C. Türk, T. Knoll, A. Petrik et al., "Guidelines on Urolithiasis," Uroweb 2014, http://www.uroweb.org/gls/pdf/22\%20Urolithiasis_LR.pdf.

[6] A. Goel and A. K. Hemal, "Upper and mid-ureteric stones: a prospective unrandomized comparison of retroperitoneoscopic and open ureterolithotomy," BJU International, vol. 88, no. 7, pp. 679-682, 2001.

[7] A. Tefekli, A. Tepeler, T. Akman et al., "The comparison of laparoscopic pyelolithotomy and percutaneous nephrolithotomy in the treatment of solitary large renal pelvic stones," Urological Research, vol. 40, no. 5, pp. 549-555, 2012.

[8] S. Chuanyu, X. Guowei, X. Ke, D. Qiang, and Z. Yuanfang, "Retroperitoneal laparoscopic dismembered Anderson-Hynes pyeloplasty in treatment of ureteropelvic junction obstruction (report of 150 cases)," Urology, vol. 74, no. 5, pp. 1036-1040, 2009.

[9] T. Fan, P. Xian, L. Yang, Y. Liu, Q. Wei, and H. Li, "Experience and learning curve of retroperitoneal laparoscopic ureterolithotomy for upper ureteral calculi," Journal of Endourology, vol. 23, no. 11, pp. 1867-1870, 2009.

[10] H. Park, M. Park, and T. Park, "Two-year experience with ureteral stones: extracorporeal shockwave lithotripsy v ureteroscopic manipulation," Journal of Endourology, vol. 12, no. 6, pp. 501-504, 1998. 
[11] P. Geavlete, D. Georgescu, G. NiţĂ, V. Mirciulescu, and V. Cauni, "Complications of 2735 retrograde semirigid ureteroscopy procedures: a single-center experience," Journal of Endourology, vol. 20, no. 3, pp. 179-185, 2006.

[12] A. R. El-Nahas, N. A. El-Tabey, I. Eraky et al., "Semirigid ureteroscopy for ureteral stones: a multivariate analysis of unfavorable results," The Journal of Urology, vol. 181, no. 3, pp. 1158-1162, 2009.

[13] T. Flasko, E. Holman, G. Kovacs, B. Tallai, C. Toth, and M. A. Salah, "Laparoscopic ureterolithotomy: the method of choice in selected cases," Journal of Laparoendoscopic and Advanced Surgical Techniques-Part A, vol. 15, no. 2, pp. 149-152, 2005.

[14] K. Kijvikai and S. Patcharatrakul, "Laparoscopic ureterolithotomy: its role and some controversial technical considerations," International Journal of Urology, vol. 13, no. 3, pp. 206-210, 2006.

[15] A. El-Feel, H. Abouel-Fettouh, and A. M. Abdel-Hakim, "Laparoscopic transperitoneal ureterolithotomy," Journal of Endourology, vol. 21, no. 1, pp. 50-54, 2007.

[16] M. G. El-Moula, A. Abdallah, F. El-Anany et al., "Laparoscopic ureterolithotomy: our experience with 74 cases," International Journal of Urology, vol. 15, no. 7, pp. 593-597, 2008.

[17] E. Huri, E. K. Basok, Ö. Uǧurlu et al., "Experiences in laparoscopic removal of upper ureteral stones: multicenter analysis of cases, based on the TurkUroLap group," Journal of Endourology, vol. 24, no. 8, pp. 1279-1282, 2010.

[18] Y. Wang, J. Hou, D. Wen, J. Ouyang, J. Meng, and H. Zhuang, "Comparative analysis of upper ureteral stones ( $>15$ $\mathrm{mm}$ ) treated with retroperitoneoscopic ureterolithotomy and ureteroscopic pneumatic lithotripsy," International Urology and Nephrology, vol. 42, no. 4, pp. 897-901, 2010.

[19] S. J. Farooq Qadri, N. Khan, and M. Khan, "Retroperitoneal laparoscopic ureterolithotomy-a single centre 10 year experience," International Journal of Surgery, vol. 9, no. 2, pp. 160-164, 2011.

[20] C. Leonardo, G. Simone, P. Rocco, S. Guaglianone, G. Di Pierro, and M. Gallucci, "Laparoscopic ureterolithotomy: minimally invasive second line treatment," International Urology and Nephrology, vol. 43, no. 3, pp. 651-654, 2011.

[21] Y. H. Ko, S. G. Kang, J. Y. Park et al., "Laparoscopic ureterolithotomy as a primary modality for large proximal ureteral calculi: comparison to rigid ureteroscopic pneumatic lithotripsy," Journal of Laparoendoscopic and Advanced Surgical Techniques, vol. 21, no. 1, pp. 7-13, 2011.

[22] H. Karami, M. M. Mazloomfard, B. Lotfi, A. Alizadeh, and B. Javanmard, "Ultrasonography-guided PNL in comparison with laparoscopic ureterolithotomy in the management of large proximal ureteral stone," International Brazilian Journal of Urology, vol. 39, no. 1, pp. 22-28, 2013.

[23] H. Nasseh, F. Pourreza, E. Kazemnejad Leyli, T. Zohari Nobijari, and H. Baghani Aval, "Laparoscopic transperitoneal ureterolithotomy: a single-center experience," Journal of Laparoendoscopic and Advanced Surgical Techniques, vol. 23, no. 6, pp. 495-499, 2013.

[24] H. Karami, B. Javanmard, A. Hasanzadeh-Hadah et al., "Is it necessary to place a Double J catheter after laparoscopic ureterolithotomy? A four-year experience," Journal of Endourology, vol. 26, no. 9, pp. 1183-1186, 2012.

[25] P. Bove, S. Micali, R. Miano et al., "Laparoscopic ureterolithotomy: a comparison between the transperitoneal and the retroperitoneal approach during the learning curve," Journal of Endourology, vol. 23, no. 6, pp. 953-957, 2009. 


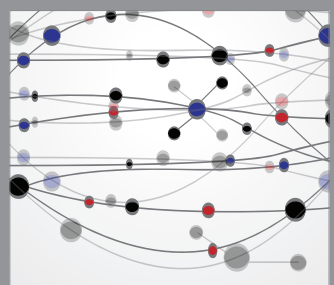

The Scientific World Journal
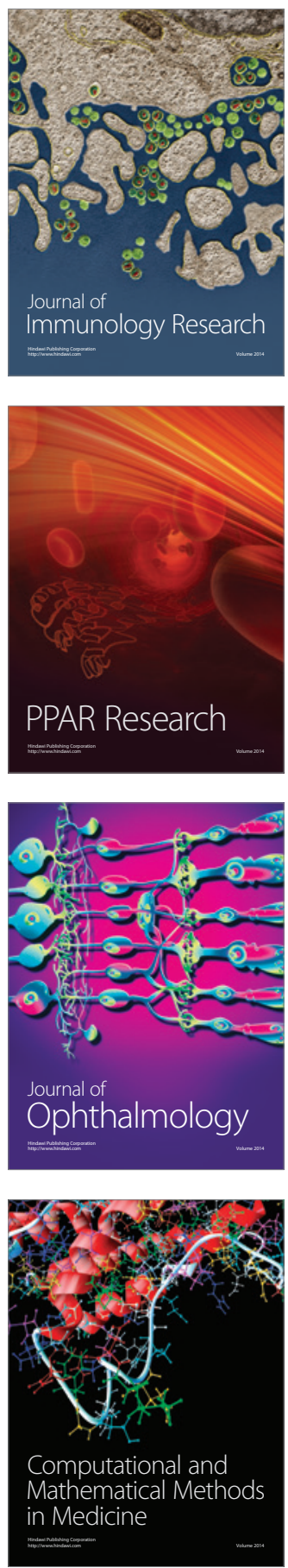

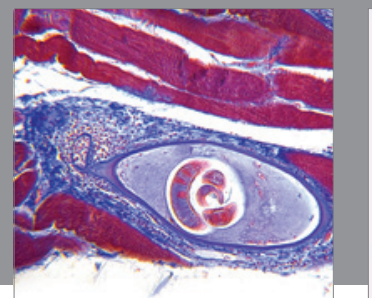

Gastroenterology

Research and Practice
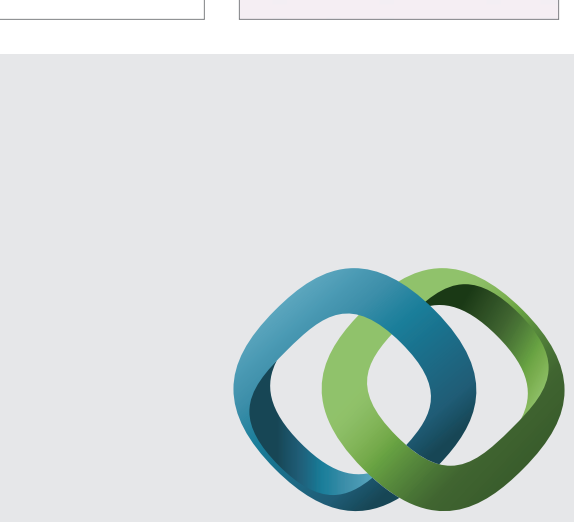

\section{Hindawi}

Submit your manuscripts at

http://www.hindawi.com
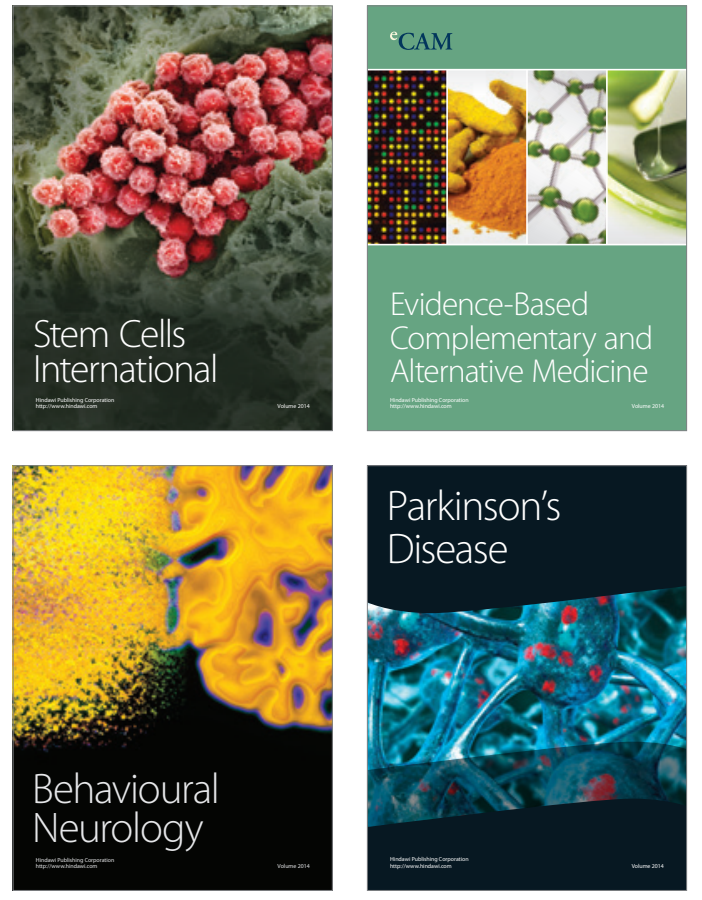
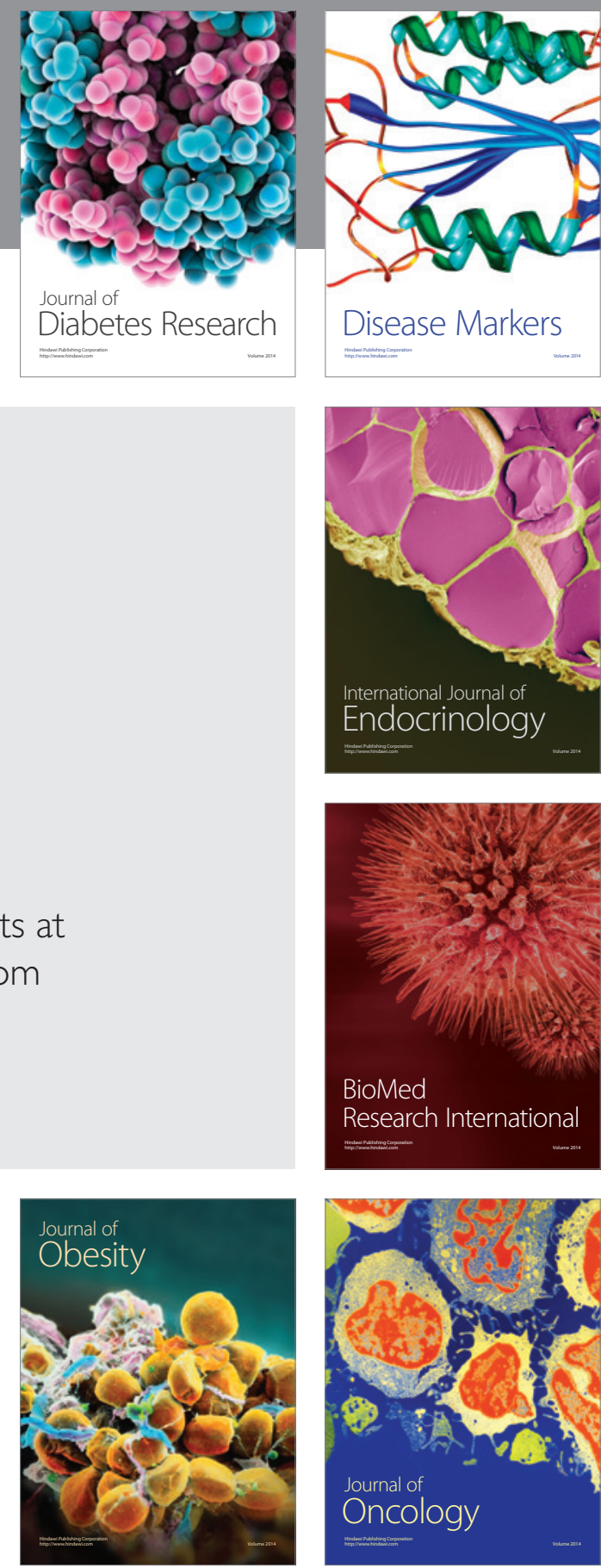

Disease Markers
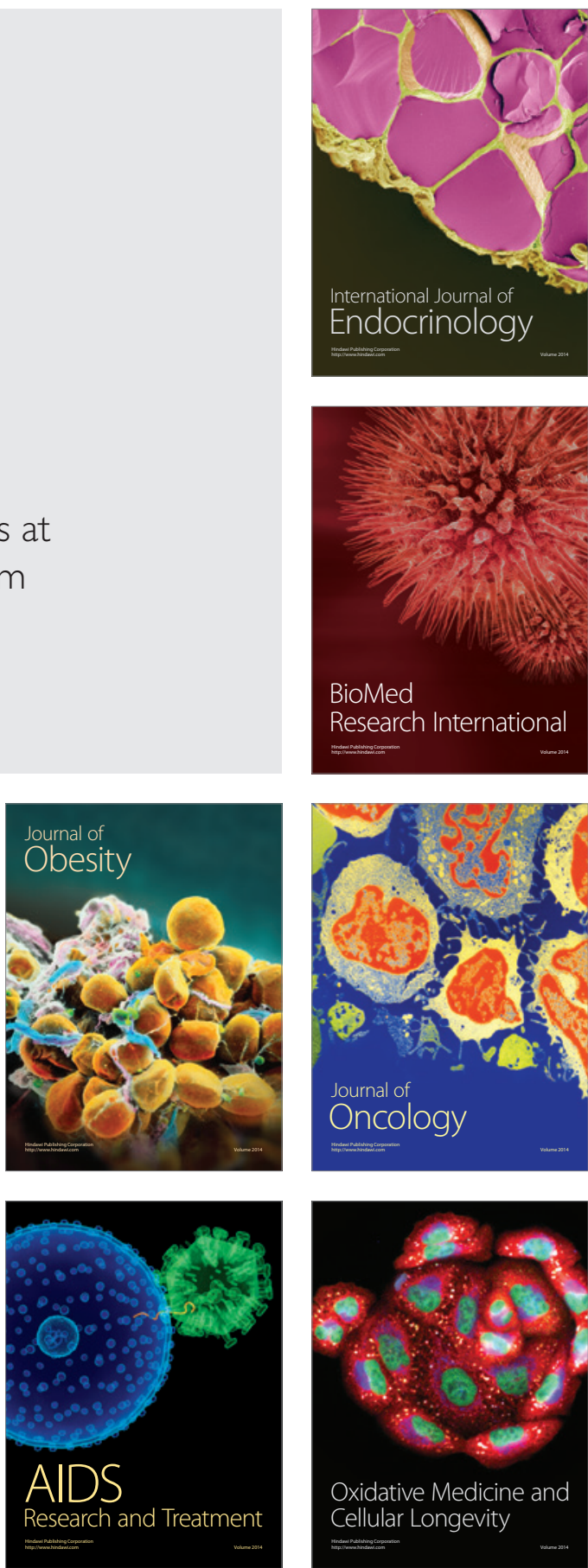